REVIEW

\title{
Interactions between the neuropeptide $Y$ system and the hypothalamic-pituitary-adrenal axis
}

Robert Krysiak, Ewa Obuchowicz and Zbigniew Stanislaw Herman

Department of Clinical Pharmacology, Silesian University School of Medicine, Medyków 18,40-752 Katowice, Poland

(Correspondence should be addressed to R Krysiak)

\begin{abstract}
The aim of this paper is to review the present knowledge of interactions between the neuropeptide $\mathrm{Y}$ (NPY) system and the hypothalamic-pituitary-adrenal (HPA) axis. On the basis of in vitro and in vivo studies of various animal species, we review the effects of NPY on all levels of HPA axis activity. We also describe the effects of glucocorticosteroids on the NPY system in the hypothalamus, including interactions between glucocorticosteroids and insulin. On the basis of available literature, we discuss the role of these interactions in the control of food intake and in the pathogenesis of obesity.
\end{abstract}

European Journal of Endocrinology 140 130-136

\section{Introduction}

Neuropeptide Y (NPY) is a 36-amino-acid peptide that belongs to the family of pancreatic polypeptides. High levels of NPY are detected in the central and peripheral nervous systems both of humans and of many animals (1). NPY functions as a neurotransmitter or neuromodulator (1), and its action is mediated by specific receptors, Y1, Y2, Y3, Y4, Y5, Y6 (2). The major effects of NPY on the central nervous system are as follows: stimulation of food intake, antianxiety effect, regulation of hormone synthesis and release, and control of circadian rhythms (3). In turn, NPY gene expression and NPY levels are regulated by many factors, among which hormones have an important role $(3,4)$.

The aim of this paper is to summarize the present knowledge of interactions between the NPY system and the hypothalamic-pituitary-adrenal (HPA) axis.

\section{Role of NPY in regulation of the HPA axis in the hypothalamus}

The hypothalamic paraventricular nucleus (PVN) is the main site of accumulation of nerve terminals of NPY-containing neurons, the perikaryons of which are located mainly in the hypothalamic arcuate nucleus (ARC) and partially in the brainstem. In the brainstem neurons, NPY is colocalized with epinephrine or norepinephrine (1). The PVN, especially its parvocellular subdivision, is the main site of synthesis of corticotropin-releasing factor (CRF) in the hypothalamus (5).
Electron microscopy has revealed synapses between NPY-containing neurons and the dendrites and cell bodies of CRF-ergic neurons (5). These synapses are asymmetric in shape, indicating a stimulatory character of transmission (6). In vitro $(7)$ and in vivo $(8,9)$ studies have revealed that NPY stimulates CRF release and increases CRF gene expression (10). Consequently, the level of pro-opiomelanocortin mRNA increases (10), as does the release of ACTH (9-11), cortisol (12), and corticosterone $(13,14)$. NPY influences the HPA axis in a dose-dependent manner $(10,15)$. In vivo, the HPA axis is stimulated by NPY given by different routes: into the lateral ventricle $(10,13)$, the third ventricle $(11,15)$, the cistern (8), intravenously (10), or directly into the PVN $(9,14)$. The greatest CRF release was induced by picomolar doses of NPY injected into the PVN, which proves that the PVN has an important role in the activation of the HPA axis by NPY. The weakest stimulatory effect of NPY on CRF secretion was observed after intravenous doses of NPY, because the permeability of the blood-brain barrier for NPY is low.

In dogs subjected to hypoglycemic stress, anti-NPY $\gamma$-globulin significantly decreased ACTH and cortisol release, indicating that endogenous NPY plays a part in the physiological regulation of the HPA axis (16). In turn, in NPY knockout mice this peptide has been shown to be unnecessary for the appropriate function of the HPA axis in animals feeding ad libitum or under acute fasting conditions (17).

It is unclear how NPY-containing nerve terminals stimulate CRF-ergic neurons. It seems that NPY directly affects CRF synthesis and release, though an indirect 
action (via influencing catecholaminergic neurotransmission) cannot be excluded. The latter is less probable, because the antagonists of $\alpha_{1}$ - and $\beta$-adrenergic receptors given at doses that block CRF release in vitro do not alter the NPY-dependent secretion of CRF (7). Also, the in vivo study by Suda et al. (10) has shown that non-selective $\alpha$ - or $\beta$-adrenergic receptor antagonists - phentolamine and propranolol respectively do not alter the effect of NPY on CRF gene expression and ACTH release. Nevertheless, other authors have suggested that an increase in CRF content after a single central injection of NPY requires normal concentrations of epinephrine and norepinephrine, and that this effect may be mediated via the $\alpha_{2}$-receptor. They observed that the depletion of these catecholamines with 6-hydroxydopamine allowed NPY to stimulate CRF release profoundly, with no evidence of altered CRF synthesis, the effect common for $\alpha_{2}$-stimulation (9).

The NPY receptor that mediates an increase in HPA axis activity is as yet unknown. In addition, results from studies of dogs and rats are inconsistent. It has been shown that only intact NPY can stimulate ACTH and cortisol release in dogs, whereas its C-terminal fragment, NPY(19-36), and the NPY analog, NPY (1-36)-OH, are ineffective (12). In contrast, Small et al. (18), using different NPY analogs, have obtained results suggesting that the rat hypothalamic NPY receptor, which increased plasma ACTH concentrations, has a fragment activation profile unlike those of $\mathrm{Y} 1-\mathrm{Y} 4$ and Y6 receptors, and appears distinct from the NPY receptor controlling food intake. They also suggest that the activity of this receptor seems to be similar to that of the Y5 receptor.

The stimulatory effect of NPY injection on HPA axis activity in rats with free access to food after NPY was stronger than the effect observed in rats that were fasted after NPY treatment (19). These data, and the concept (which is not accepted by all authors) that an overnight fast reduces the corticosterone response to NPY, suggest that NPY may be involved in the integration of the activities of the hypothalamic feeding system and the HPA axis $(19,20)$.

\section{Role of NPY in regulation of the HPA axis in the pituitary gland}

Although the anterior pituitary is devoid of NPYcontaining nerves (21), it is likely that the pituitary gland is directly involved in the physiological regulation of the HPA axis by NPY, because large amounts of NPY are released from the hypothalamus to the pituitary portal circulation (22). However, the effect of NPY at the level of the pituitary gland seems to be weaker than that in the hypothalamus and is speciesdependent $(11,15)$. In the study by Brooks et al. (11), NPY did not affect ACTH release in the cultures of pituitary cells from adult and fetal sheep, whereas ACTH release increased in the sheep pituitary in situ. These findings suggest that ACTH secretion is indirectly enhanced as a result of NPY acting at one or more suprahypophysial brain sites. Moreover, NPY did not alter the CRF-stimulated release of ACTH in sheep, and it did not modulate the ability of cortisol to inhibit CRF induced ACTH secretion (11). In contrast, NPY stimulates HPA axis activity in the dog pituitary, because NPY injected in subthreshold doses into the third ventricle potentiates the effect of CRF on ACTH release (15).

\section{Role of NPY in regulation of the HPA axis in adrenal glands}

NPY is likely to be involved in the regulation of HPA axis activity in the adrenal glands, because NPY-containing neurons have been found in the adrenal capsule and zona glomerulosa (ZG) and NPY-binding sites have been detected in the ZG (23). Acute administration of NPY to rats increases the concentrations of circulating aldosterone (24) and enhances the release of aldosterone in adrenals perfused in situ (25) and through isolated specimens of the adrenal capsule and ZG (26). Chronic administration of NPY to rats with damaged HPA axis and renin-angiotensin system (RAS) stimulates ZG to grow and to synthesize steroids (27). NPY also modifies the ACTH-dependent release of aldosterone. At low ACTH concentrations (comparable to those in plasma) NPY stimulates the steroidogenic response in $\mathrm{ZG}$, which is reflected by increased aldosterone secretion. At high ACTH concentrations, NPY inhibits the stimulatory effect of ACTH on the release of aldosterone (28). These changes are reflected by the concentrations of cAMP. Although NPY does not affect cAMP concentrations in the adrenal cortex, it modifies ACTH-induced increases in cAMP, namely it increases ACTH-dependent cAMP concentrations at low concentrations of ACTH, and decreases cAMP concentrations at high concentrations of ACTH (28). However, the significance of the stimulatory effect of NPY on the synthesis and release of aldosterone is not very important. This view is based on studies that have demonstrated that the NPY receptor antagonist, Ac-[3(2,6-dichlorobenzyl)-Tyr ${ }^{27}$,D-Thr $\left.{ }^{32}\right] \mathrm{NPY}(27-36)$ (PYX2), does not alter aldosterone release, despite blocking NPY-induced aldosterone secretion (23), and that an NPY-induced increase in aldosterone release is relatively small (29).

Reports concerning the influence of NPY on corticosterone secretion by the adrenals are contradictory. Some authors believe that NPY does not influence the release of corticosterone, because it did not affect corticosterone secretion in intact and ACTH-stimulated cells of the zonae fasciculata/reticularis (28). Moreover, prolonged administration of NPY to rats with damaged HPA axis and RAS did not stimulate the growth of the 
zona fasciculata and did not alter the plasma corticosterone concentrations (27). In contrast, Malendowicz et al. (30) observed that NPY inhibited release of corticosterone from both intact and ACTH-stimulated adrenal cells, and Neri et al. (31) demonstrated that NPY increased corticosterone release in vitro.

It seems that the role of NPY in the physiological regulation of the HPA axis is of less importance in the adrenal glands than in the hypothalamus.

\section{Regulation of the hypothalamic NPY system by adrenal steroids}

There are two types of glucocorticoid receptors. Type I receptors have high affinity and low capacity, and type II receptors have lower affinity for corticosteroids (32). In physiological conditions, type I receptors are stimulated tonically because they are highly sensitive to glucocorticosteroids, whereas type II receptors are stimulated only if their concentrations are relatively high, for example, at the peak of circadian release of corticosterone or after stress (32). The type I receptor is often called the mineralocorticosteroid receptor because it has high affinity for aldosterone and it is located in aldosterone-dependent organs, such as the kidneys, salivary glands, and intestine. In the central nervous system, type I receptors have been detected mainly in the limbic system, whereas type II receptors are present in the hypothalamus (32).

The sensitivity of NPY-containing hypothalamic neurons to corticosteroids depends on the density of intracellular and membrane-bound type II glucocorticosteroid receptors. In hypothalamic structures of low receptor density, such as the supraoptic nucleus and lateral part of the paraventricular nucleus, glucocorticosteroids produce a slight increase in NPY immunoreactivity (33). In contrast, in hypothalamic structures of very high receptor density, such as the median part of the paraventricular nucleus, NPY activity responds to glucocorticosteroid administration, and it is conditioned by the concentrations of endogenous corticosterone in plasma (34). The important role of the type II receptor in influencing the NPY system through glucocorticosteroids (Fig. 1) has been confirmed by the following findings: (i) dexamethasone (DEX), a selective stimulator of type II receptors, increased the concentrations of NPY mRNA, NPY, or both, in the basomedial hypothalamus (35), the ARC (36), the PVN $(36,37)$, and in hypothalamic cell culture (this effect was blocked by the type II receptor antagonist, RU 486) (38); (ii) RU 486 (mifepristone), unlike the type I antagonist, RU 318, blocks the effect of NPY on food intake (39); and (iii) circadian NPY activity correlates with circadian corticosterone, but not aldosterone activity (40). An additional piece of evidence for a role of the type II receptor in the regulation of the NPY system in the hypothalamus is that some authors have not detected any changes in the concentrations of NPY mRNA and NPY in the ARC in adrenalectomized rats (41). Other authors, however, question these results, as they have found a decrease in NPY gene expression (42) and in NPY concentrations in the ARC (43). Moreover, adrenalectomy does not alter NPY concentrations in hypothalamic areas, where NPY is contained mainly in the nerve terminals $(34,41)$, except for hypothalamic structures with particularly abundant terminals of NPY-containing neurons, namely the parvocellular area of the PVN, the dorsomedial nucleus, and the medial preoptic area, where adrenalectomy decreases NPY immunoreactivity (34).

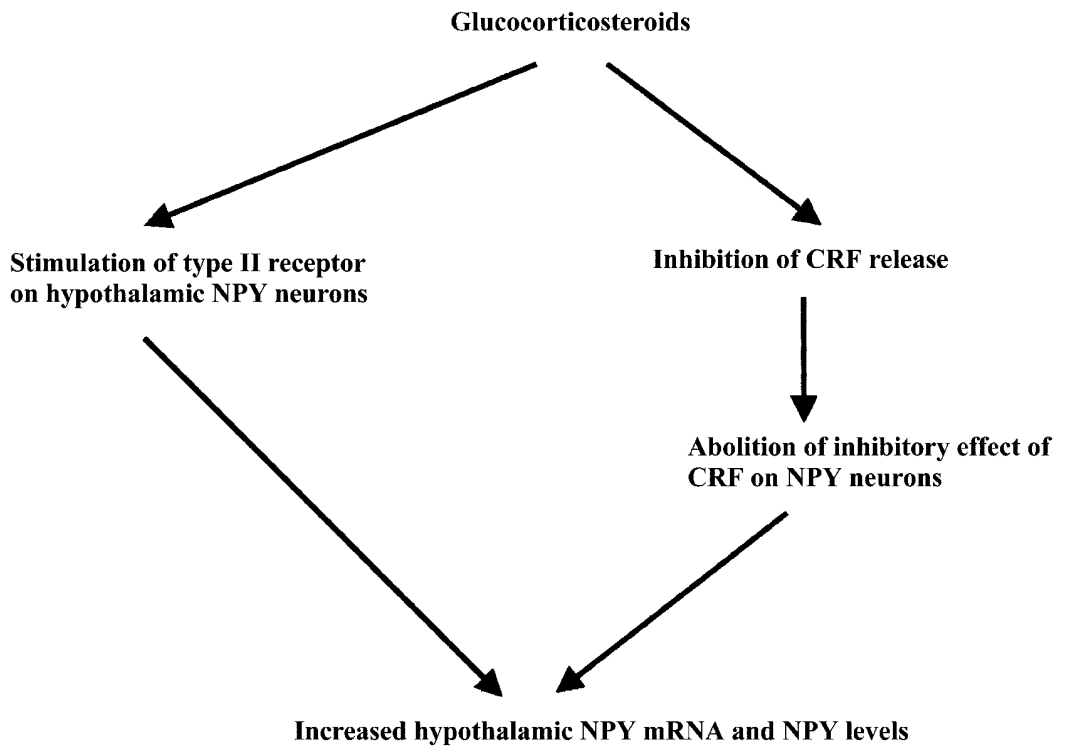

Increased hypothalamic NPY mRNA and NPY levels
Figure 1 Major pathways of regulation of the hypothalamic NPY system by glucocorticosteroids. 
Chronic administration of corticosterone to adrenalectomized rats increases NPY system activity in the ARC and locus coeruleus, the sites of NPY synthesis. This increased NPY activity is confirmed by increases in NPY gene expression, NPY concentrations, Y1 receptor mRNA levels, and in the affinity of this receptor for ${ }^{125}$ I-labelled peptide YY $(34,44)$. The results of the studies conducted on adrenalectomized rats indicate that the influence of adrenal steroids is significantly more pronounced in these animals than in intact ones (34). According to Ponsalle et al. (45), glucocorticosteroids are indispensable to an increase in NPY mRNA in fasted animals; however, some authors do not share this opinion $(46,47)$.

Moreover, glucocorticosteroids are able to control NPY gene expression in hypothalamic structures belonging to the hypothalamic-neurohypophysial system. This is supported by the finding that adrenalectomy increases NPY mRNA concentrations in these structures, probably as a result of the augmentation of plasma osmolarity, and that this increase is abolished by DEX treatment. The increased NPY gene expression after adrenalectomy is not paralleled by increased NPY concentrations, probably because of disturbances in translation, lower intracellular capacity, or enhanced axonal flow resulting in rapid release of newly synthesized peptide $(33,48)$.

The influence of glucocorticosteroids on the hypothalamic NPY system is not only direct, but also indirect, via the CRF system (Fig. 1). Chronic administration of CRF into the hypothalamus decreases food intake, body weight gain, and insulinemia in rats (32). These effects are opposite to the action of NPY (3). CRF inhibits NPY synthesis and release $(3,49)$ and decreases NPY-induced food intake (32). Glucocorticosteroids inhibit the release of CRF, thus abolishing its inhibitory effect on NPY-ergic neurons and shifting the balance between NPY and CRF in favor of the former.

An interaction between corticosterone and hypothalamic NPY neurons is important for the circadian rhythmicity of some physiological processes, such as food intake, locomotor activity, corticosterone secretion, and occupation of the type II glucocorticosteroid receptor, all of which are strongest at the beginning of the active phase of circadian cycle (34).

\section{Involvement of complex interactions between the HPA axis and the NPY system in regulation of food intake and pathogenesis of obesity}

The important role of corticosteroids in the control of NPY activity has been confirmed by the facts that adrenalectomy or hypophysectomy inhibits the stimulatory effect of NPY on food intake $(50,51)$ and that adrenalectomy reverses the increased body weight and plasma concentrations of corticosterone, insulin and triglyceride observed after several days of NPY treatment in intact rats (13).

Strack et al. (52) suggested that glucocorticosteroids and insulin are major antagonistic regulators of energy balance and that their long-term effects on food intake are in part mediated by the regulation of hypothalamic NPY synthesis and release. In contrast to the relationship between NPY and steroids, the relationship between the hypothalamic NPY system and insulin possesses the feature of negative feedback (3). The ARC contains abundant insulin receptors, and insulin decreases the concentrations of NPY and its mRNA in this structure (53). In the hypothalamus of diabetic rats, hypoinsulinemia is accompanied by increased synthesis and concentrations of NPY $(38,53)$. Insulin also regulates the feedback between glucocorticosteroids and NPY, because it inhibits DEX-induced NPY gene expression in the ARC and increases in NPY concentrations in the ARC and PVN (36).

The opposing effects of insulin and glucocorticosteroids on the hypothalamic NPY system are very important for the regulation of food intake (52). However, it should be borne in mind that NPY activity is also modulated by other factors, such as $\beta$-endorphin, serotonin and leptin - a recently discovered fat tissue hormone of potent anorexigenic activity. All these factors influence hypothalamic NPY concentrations and NPY gene expression via both direct and indirect mechanisms, and the net effect results from their mutual interactions (4). This complex regulation may explain the failure of some authors to find and parallel changes in NPY gene expression in the basomedial hypothalamus,, in NPY release in the $\mathrm{PVN}$, and in plasma corticosterone concentrations in fasted animals $(46,47)$.

The positive feedback between corticosterone and NPY, which has an important role in the central regulation of food intake, in pathological conditions may produce a 'vicious circle' of events. This has been shown in obese Zucker rats, obese ob/ob mice, patients with anorexia nervosa, animals and humans exposed to stress and to glucocorticosteroids $(44,52,54)$.

Obese Zucker rats exhibit increased NPY mRNA and NPY concentrations in the ARC and PVN respectively, which led to increased NPY release (55). The altered activity of the hypothalamic NPY system in these rats results, not only from insensitivity to insulin (53) and mutations of the leptin receptor (4), but also from increased plasma corticosterone concentrations (56) and increased sensitivity to corticosterone (57). In turn, NPY increases, via a positive feedback, plasma corticosterone concentrations (32). Such a vicious circle of events occurring in these conditions is confirmed by the finding that adrenalectomy (58) and hypophysectomy in these rats (59) reduce most symptoms of obesity.

In ob/ob mice, obesity is caused by a genetic disturbance of leptin synthesis. Leptin reverses increases 
Table 1 Effects of NPY on various components of the HPA axis

\begin{tabular}{|c|c|c|c|c|}
\hline Site of action & Type of action & Animal species & Effect & Remarks \\
\hline Hypothalamus & Direct & Rat, sheep, dog & $\begin{array}{l}\text { Increased CRF synthesis } \\
\text { and release }\end{array}$ & $\begin{array}{l}\text { The main site of the HPA axis } \\
\text { that is stimulated by NPY }\end{array}$ \\
\hline \multirow[t]{2}{*}{ Pituitary gland } & Indirect & Rat, sheep, dog & Enhanced secretion of ACTH & $\begin{array}{l}\text { Indirect effect on hypothalamic } \\
\text { levels is more important than } \\
\text { direct effect }\end{array}$ \\
\hline & Direct & $\begin{array}{l}\text { Sheep } \\
\text { Dog }\end{array}$ & $\begin{array}{l}\text { No effect } \\
\text { Potentiation of CRF-induced } \\
\text { ACTH secretion }\end{array}$ & $\begin{array}{l}\text { Direct effect depends on animal } \\
\text { species }\end{array}$ \\
\hline \multirow[t]{2}{*}{ Adrenal glands } & Indirect & Rat, sheep, dog & $\begin{array}{l}\text { Increased corticosterone or } \\
\text { cortisol release } \\
\text { Increased aldosterone } \\
\text { synthesis and release }\end{array}$ & $\begin{array}{l}\text { Indirect effect (secondary to } \\
\text { enhanced secretion of } \\
\text { ACTH) is more important } \\
\text { than direct effect }\end{array}$ \\
\hline & Direct & Rat & $\begin{array}{l}\text { Modulation of ACTH-induced } \\
\text { aldosterone secretion } \\
\text { Contradictory results for } \\
\text { corticosterone release }\end{array}$ & \\
\hline
\end{tabular}

in the hypothalamic NPY mRNA and NPY concentrations (4) and enhanced HPA axis activity that are observed in these mice (60). Because, in intact rats, leptin blocks corticosterone-induced NPY release (61), it is not suprising that, in adrenalectomized ob/ob mice, glucocorticosteroids accelerate hypothalamic NPY axonal transfer and release in the PVN (62). It is likely that high corticosterone concentrations and increased NPY system activity observed in ob/ob mice may produce a vicious circle of events. This suggestion is supported by the fact that adrenalectomy normalizes many metabolic defects in ob/ob mice $(4,62)$.

It has been found that patients with anorexia nervosa have increased NPY concentrations in their cerebrospinal fluid (63). The contradiction between decreased food intake in anorexia nervosa and increased concentrations of NPY (which stimulates food intake) may be explained by a masking of hunger by the discomfort associated with eating (63). The increased NPY concentrations in cerebrospinal fluid from patients with anorexia nervosa may result from increased NPY synthesis, transport and release induced by the increased plasma concentrations of ACTH and cortisol in these patients (64). This suggestion may be confirmed by a decrease in cortisol and NPY concentrations after the normalization of body weight $(63,65)$.

Chronic stress or administration of glucocorticosteroid increase both glucocorticosteroids and insulin in plasma, while their ratio remains normal (52). Consequently, energetic compounds start to accumulate in abdominal adipose tissue instead of muscle tissue. It is likely that some types of abdominal obesity may be due to increased HPA axis activity (54). As corticosterone increases food intake and carbohydrate consumption, a prolonged excess of corticosterone may lead to obesity and insulin resistance, in which the hypothalamic NPY system may play a significant part $(52,54)$.

\section{Conclusions}

The relationship between the NPY system and the HPA axis is complex (Table 1) and seems to include positive feedback between NPY and adrenal corticosteroids and negative feedback between CRF and NPY. The stimulation of the HPA axis by NPY takes place mainly in the hypothalamus, primarily as a result of increased CRF synthesis in the PVN and increased CRF release in the median eminence. The role of NPY in the regulation of the HPA axis in the pituitary and adrenal glands is of less significance, but cannot be excluded. In the pituitary, the effects of NPY vary from animal to animal. In the adrenal cortex, the effect of NPY is strongest in the ZG, where NPY affects the synthesis and release of aldosterone. Glucocorticosteroids increase NPY and NPY mRNA concentrations in the rat hypothalamus, and their effects on the hypothalamic NPY system are primarily due to the stimulation of the type II receptor. The feedback loop between glucocorticosteroids and NPY plays a significant part in the regulation of their metabolic functions, and any disturbance may be conducive to metabolic diseases. The activity of the NPY system is also regulated by other factors, among which insulin has an important role. Despite extensive research into the relationship between the NPY system and the HPA axis, not all issues have yet been clarified and therefore they require further study.

\section{References}

1 Heilig M \& Widerlov E. Neurobiology and clinical aspects of neuropeptide Y. Critical Reviews in Neurobiology 19959 115-136. 
2 Balasubramaniam A. Neuropeptide Y family of hormones: receptor subtypes and antagonists. Peptides 1997 3 445-457.

3 White JD. Neuropeptide Y: a central regulator of energy homeostasis. Regulatory Peptides 199349 93-107.

4 Rohner-Jeanrenaud E \& Jeanrenaud B. Central nervous system and body weight regulation. Annales d'Endocrinologie 199758 $137-142$

5 Liposits Z, Sievers L \& Paull WK. Neuropeptide-Y and ACTHimmunoreactive innervation of corticotropin releasing factor (CRF)-synthesizing neurons in the hypothalamus of the rat. An immunocytochemical analysis at the light and electron microscopic levels. Histochemistry $1988 \mathbf{8 8} 227-234$.

6 Cohen RS, Carlin RK, Grab DJ \& Siekewitz P. Phosphoproteins in postsynaptic densities. Progress in Brain Research 198256 49-76.

7 Tsagarakis S, Rees LH, Besser GM \& Grossman A. Neuropeptide Y stimulates CRF-41 release from rat hypothalami in vitro. Brain Research 1989502 167-170.

8 Haas DA \& George SR. Neuropeptide Y administration acutely increases hypothalamic corticotropin-releasing factor immunoreactivity: lack of effect in other rat brain regions. Life Sciences $1987412725-2731$.

9 Haas DA \& George SR. Neuropeptide Y-induced effects on hypothalamic corticotropin-releasing factor content and release are dependent on noradrenergic/adrenergic neurotransmission. Brain Research 1989498 333-338.

10 Suda T, Tozawa F, Iwai I, Sato Y, Sumitomo T, Nakano Y, Yamada M \& Demura H. Neuropeptide $\mathrm{Y}$ increases the corticotropin-releasing factor messenger ribonucleic acid level in the rat hypothalamus. Molecular Brain Research 199318311 315.

11 Brooks AN, Howe DC, Porter DW \& Naylor AM. Neuropeptide Y stimulates pituitary-adrenal activity in fetal and adult sheep. Journal of Neuroendocrinology 19946 161-166.

12 Miura M, Inui A, Teranishi A, Hirosue Y, Nakajima M, Okita M, Inoue T, Baba $S$ \& Kasuga M. Structural requirements for the effects of neuropeptide $\mathrm{Y}$ on the hypothalamic-pituitary-adrenal axis in the dog. Neuropeptides $19922315-18$

13 Sainsbury A, Rohner-Jeanrenaud F, Grouzmann E \& Jeanrenaud B. Acute intracerebroventricular administration of neuropeptide Y stimulates corticosterone output and feeding but not insulin output in normal rats. Neuroendocrinology 199663 318-326.

14 Albers HE, Ottenweller JE, Liou SY, Lumpkin MD \& Anderson ER Neuropeptide Y in the hypothalamus: effect on corticosterone and single-unit activity. American Journal of Physiology 1990258 R376-R382.

15 Inoue T, Inui A, Okita M, Sakatani N, Oya M, Morioka H, Mizuno N, Oimomi M \& Baba S. Effect of neuropeptide Y on the hypothalamic-pituitary-adrenal axis in the dog. Life Sciences $1989441043-1051$

16 Inui A, Inoue T, Nakajim M, Okita M, Sakatani N, Okimura Y, Chihara K \& Baba S. Brain neuropeptide $\mathrm{Y}$ in the control of adrenocorticotropic hormone secretion in the dog. Brain Research $1990510211-215$.

17 Erickson JC, Ahima RS, Hollopeter G, Flier JS \& Palmiter RD. Endocrine function of neuropeptide Y knockout mice. Regulatory Peptides 199770 199-202.

18 Small CJ, Morgan DG, Meeran K, Heath MM, Gunn I, Edwards CM, Gardiner J, Taylor GM, Hurley JD, Rossi M, Goldstone AP O'Shea D, Smith DM, Ghatei MA \& Bloom SR. Peptide analogue studies of the hypothalamic neuropeptide $\mathrm{Y}$ receptor mediating pituitary adrenocorticotrophic hormone release. Proceedings of the National Academy of Sciences of the USA 199794 11686-11691.

19 Hanson ES \& Dallman MF. Neuropeptide Y (NPY) may integrate responses of hypothalamic feeding systems and the hypothalamo-pituitary-adrenal axis. Journal of Neuroendocrinology $19957273-279$.

20 Parikh R \& Marks JL. Metabolic and orexigenic effects of intracerebroventricular neuropeptide $\mathrm{Y}$ are attenuated by food deprivation. Journal of Neuroendocrinology 1997 9 789-795.
21 Vanhatalo S \& Soinila S. Pituitary gland receives both central and peripheral neuropeptide Y innervation. Brain Research 1996740 253-260.

22 McDonald JK, Koenig JI, Gibbs DM, Collins P \& Noe BD. High concentrations of neuropeptide $\mathrm{Y}$ in pituitary portal blood of rats. Neuroendocrinology 198746 538-541.

23 Mazzocchi G, Malendowicz LK, Macchi C, Gottardo G \& Nussdorfer GG. Further investigations on the effects of neuropeptide $\mathrm{Y}$ on the secretion and growth of rat adrenal zona glomerulosa. Neuropeptides 199630 19-27.

24 Mazzocchi G \& Nussdorfer GG. Neuropeptide Y acutely stimulates rat zona glomerulosa in vivo. Neuropeptides $19879257-262$.

25 Hinson JP, Cameron LA, Purbrick A \& Kapas S. The role of neuropeptides in the regulation of adrenal zona glomerulosa function: effects of substance $\mathrm{P}$, neuropeptide $\mathrm{Y}$, neurotensin, Met-enkephalin, Leu-enkephalin and corticotrophin-releasing hormone on aldosterone secretion in the intact perfused rat adrenal. Journal of Endocrinology 1994140 91-96.

26 Bernet F, Maubert E, Bernard J, Montel V \& Dupouy JP. In vitro steroidogenic effects of neuropeptide Y (NPY1-36), Y1 and Y2 receptor agonists (Leu ${ }^{31}$-Pro ${ }^{34}$ NPY, NPY18-36) and peptide YY (PYY) on rat adrenal capsule/zona glomerulosa. Regulatory Peptides 199452 187-193.

27 Rebuffat P, Malendowicz LK, Belloni AS, Mazzocchi G \& Nussdorfer GG. Long-term stimulatory effect of neuropeptide Y on the growth and steroidogenic capacity of rat adrenal zona glomerulosa. Neuropeptides 198811 133-136.

28 Hinson JP, Cameron LA \& Kapas S. Neuropeptide Y modulates the sensitivity of the rat adrenal cortex to stimulation by ACTH. Journal of Endocrinology 1995145 283-289.

29 Hinson JP, Purbrick A, Cameron LA \& Kapas S. The role of neuropeptides in the regulation of adrenal zona fasciculata/ reticularis function. Effects of vasoactive intestinal polypeptide, substance P, neuropeptide Y, Met- and Leu-enkephalin and neurotensin on corticosterone secretion in the intact perfused rat adrenal gland in situ. Neuropeptides 199426 391-397.

30 Malendowicz LK, Lesniewska B \& Miskowiak B. Neuropeptide Y inhibits corticosterone secretion by isolated adrenocortical cells. Experientia $199046721-722$.

31 Neri G, Andreis PG \& Nussdorfer GG. Effects of neuropeptide Y and substance $\mathrm{P}$ on the secretory activity of dispersed zona glomerulosa cells of rat adrenal gland. Neuropeptides 199017 121-125.

32 Tempel DL \& Leibowitz SF. Adrenal steroid receptors: interactions with brain neuropeptide systems in relation to nutrient intake and metabolism. Journal of Neuroendocrinology 19946 479-501.

33 Larsen PJ, Mikkelsen JD, Jessop DS, Lightman SL \& Chowdrey HS. Neuropeptide Y mRNA and immunoreactivity in hypothalamic neuroendocrine neurons: effects of adrenalectomy and chronic osmotic stimulation. Journal of Neuroscience $1993131138-$ 1147.

34 Akabayashi A, Watanabe Y, Wahlestedt C, McEwen BS, Paez X \& Leibowitz SF. Hypothalamic neuropeptide Y, its gene expression and receptor activity: relation to circulating corticosterone in adrenalectomized rats. Brain Research 1994665 201-212.

35 White BD, Dean RG, Edwards GL \& Martin RJ. Type II corticosteroid receptor stimulation increases NPY gene expression in the basomedial hypothalamus of rats. American Journal of Physiology 1994266 R1523-1529.

36 Wilding JPH, Gilbey SG, Lambert PD, Ghatei MA \& Bloom SR. Increases in neuropeptide Y content and gene expression in the hypothalamus of rats treated with dexamethasone are prevented by insulin. Neuroendocrinology 199357 581-587.

37 McKibbin PE, Cotton SJ, McCarthy HD \& Williams G. The effect of dexamethasone on neuropeptide $\mathrm{Y}$ concentrations in specific hypothalamic regions. Life Sciences $1992511301-$ 1307.

38 Barnea A, Cho G, Hajibeigi A, Aguila MC \& Magni P. Dexamethasone-induced accumulation of neuropeptide $\mathrm{Y}$ by 
aggregating fetal brain cells in culture: a process dependent on the developmental age of the aggregates. Endocrinology 1991129 231-238.

39 Tempel DL \& Leibowitz SF. Glucocorticoid receptors in the PVN: interactions with norepinephrine, neuropeptide $\mathrm{Y}$ and galanin in relation to feeding. American Journal of Physiology 1993265 E794-E800.

40 Akabayashi A, Levin N, Paez X, Alexander JT \& Leibowitz SF. Hypothalamic neuropeptide $\mathrm{Y}$ and its gene expression: relation to light/dark cycle and circulating corticosterone. Molecular and Cellular Neurosciences 19945 210-218.

41 Rivet JM, Castagne V, Corder R, Gaillard R \& Mormede P. Study of the influence of stress and adrenalectomy on central and peripheral neuropeptide Y levels. Comparison with catecholamines. Neuroendocrinology $198950413-420$

42 White BD, Dean RG \& Martin RJ. Adrenalectomy decreases neuropeptide $\mathrm{Y}$ mRNA levels in the arcuate nucleus. Brain Research Bulletin 199025 711-715.

43 Pralong FP, Corder R, \& Gaillard RC. The effects of chronic glucocorticoid excess, adrenalectomy and stress on neuropeptide Y in individual rat hypothalamic nuclei. Neuropeptides 199325 223-231.

44 Larsen PJ, Jessop DS, Chowdrey HS, Lightman SL \& Mikkelsen JD. Chronic administration of glucocorticoids directly upregulates prepro-neuropeptide $\mathrm{Y}$ and Y1-receptor mRNA levels in the arcuate nucleus of the rat. Journal of Neuroendocrinology 19946 153-159.

45 Ponsalle P, Srivastava LS, Uht RM \& White JD. Glucocorticoids are required for food deprivation-induced increases in hypothalamic neuropeptide Y expression. Journal of Neuroendocrinology 19934 585-591.

46 Hanson ES, Levin N \& Dallmann MF. Elevated corticosterone is not required for the rapid induction of neuropeptide $\mathrm{Y}$ gene expression by an overnight fast. Endocrinology $19971381041-$ 1047.

47 Yoshihara T, Honma S, Katsuno Y \& Honma K. Dissociation of paraventricular NPY release and plasma corticosterone levels in rats under food deprivation. American Journal of Physiology 1996 271 E239-E245.

48 Larsen PJ, Sheikh SP \& Mikkelsen JD. Osmotic regulation of neuropeptide $\mathrm{Y}$ and its binding sites in the magnocellular hypothalamo-neurohypophysial pathway. Brain Research 1992 573 181-189.

49 Van Huijsduijnen OB, Rohner-Jeanrenaud F \& Jeanrenaud B. Hypothalamic neuropeptide Y messenger ribonucleic acid levels in pre-obese and genetically obese ( $\mathrm{fa} / \mathrm{fa}$ ) rats; potential regulation thereof by corticotropin-releasing factor. Journal of Neuroendocrinology $19935381-386$.

50 Sainsbury A, Cusin I, Rohner-Jeanrenaud F \& Jeanrenaud B. Adrenalectomy prevents the obesity syndrome produced by chronic central neuropeptide Y infusion in normal rats. Diabetes 199746 209-214.

51 Stanley BG, Lanthier D, Chin AS \& Leibowitz SF. Suppression of neuropeptide Y-elicited eating by adrenalectomy or hypophysectomy: reversal with corticosterone. Brain Research 1989 $50132-36$.
52 Strack AM, Sebastian RJ, Schwartz MW \& Dallman MF. Glucocorticoids and insulin: reciprocal signals for energy balance. American Journal of Physiology 1995268 R142-R149.

53 Schwartz MW, Figlewicz DP, Baskin DG, Woods SC \& Porte D. Insulin in the brain: a hormonal regulator of energy balance. Endocrine Reviews 199213 387-404.

54 Dallman MF, Akana SF, Strack AM, Hanson ES \& Sebastian RJ. The neural network that regulates energy balance is responsive to glucocorticoids and insulin and also regulates HPA axis responsivity at a site proximal to CRF neurons. Annals of the New York Academy of Sciences 1995771 730-742.

55 Dryden S, Pickavance L, Frankish HM \& Williams G. Increased neuropeptide $\mathrm{Y}$ secretion in the hypothalamic paraventricular nucleus of obese (fa/fa) Zucker rats. Brain Research 1995690 185-188.

56 Guillaume-Gentil CF, Rohner-Jeanranaud F, Abramo F, Bestetti GE, Rossi GL \& Jeanranaud B. Abnormal regulation of the hypothalamo-pituitary-adrenal axis in the genetically obese fa/fa rat. Endocrinology 1990126 1873-1879.

57 Freedman MR, Horwitz BA \& Stern JS. Effects of adrenalectomy and glucocorticoid replacement on development of obesity. American Journal of Physiology 1986250 R595-R607.

58 Yukimura \& Bray GA. Effects of adrenalectomy on body weight and the size and number of fat cells in the Zucker (fatty) rat. Endocrine Research 19785 189-198.

59 Powley T \& Morton S. Hypophysectomy and regulation of body weight in genetically obese Zucker rats. American Journal of Physiology $1976230982-987$.

60 Heiman ML, Ahima RS, Craft LS, Schoner B, Stephens TW \& Flier JS. Leptin inhibition of the hypothalamic-pituitary-adrenal axis in response to stress. Endocrinology 1997138 3859-3863

61 Stephens TW, Basinski M, Bristow PK, Bue-Valleskey JM, Burgett SG, Craft L, Hale J, Hoffmann J, Hsiung HM, Kriauciunas A, McKellar W, Rosteck PR Jr, Schoner B, Smith D, Tinsley FC, Zhang XY \& Heiman M. The role of neuropeptide $\mathrm{Y}$ in the antiobesity action of the obese gene product. Nature 1995377 530-532.

62 Chen HL \& Romsos DR. Dexamethasone rapidly increases hypothalamic neuropeptide Y secretion in adrenalectomized $o b /$ ob mice. American Journal of Physiology 1996271 E151-E158.

63 Kaye WH, Berrettini W, Gwirtsman H \& George DT. Altered cerebrospinal fluid neuropeptide $\mathrm{Y}$ and peptide YY immunoreactivity in anorexia and bulemia nervosa. Archives of General Psychiatry 199047 548-556.

64 Hotta M, Shibasaki T, Masuda A, Imaki T, Demura H, Ling N \& Shizume K. The responses of plasma adrenocorticotropin and cortisol to corticotropin-releasing hormone (CRH) and cerebrospinal fluid immunoreactive $\mathrm{CRH}$ in anorexia nervosa patients. Journal of Clinical Endocrinology and Metabolism 198662 319-324.

65 Walsh BT, Katz JL, Levin J, Kream J, Fukushima DK, Weiner H \& Zumoff $\mathrm{B}$. The production rate of cortisol declines during recovery from anorexia nervosa. Journal of Clinical Endocrinology and Metabolism 198153 203-205.

Received 16 October 1998

Accepted 16 October 1998 